\title{
LA COMUNIDAD INCONCLUSA: DON GUILLERMO DE JOSÉ VICTORINO LASTARRIA
}

\author{
Felipe González Alfonso \\ Pontificia Universidad Católica de Valparaíso \\ Valparaíso, Chile \\ felipe.gonzalez.a@pucv.cl
}

RESUMEN / ABSTRACT

La novela Don Guillermo (1860) de José Victorino Lastarria (1817-1888) incorpora el espaciotiempo de Valparaíso durante los decenios conservadores de 1830 a 1860, emergente espacio del capital y a la vez foco revolucionario, esto último debido a la geografía de la ciudad, su tradición gremial y la agitación política por parte de grupos ilustrados y radicales. Teniendo en cuenta este subtexto histórico y articulando los conceptos de "espacio", "imaginarios" y "comunidad" mediante el concepto de "cronotopo", este trabajo indaga principalmente la representación del espacio porteño en el texto literario. Desde esta perspectiva, la novela de Lastarria se propone como "antiutopía" en el espacio de La cueva del Chivato, y como "utopía" liberal en el espacio modernizado de Valparaíso, estableciendo una negociación simbólica con el rol de la comunidad británica en la ciudad.

Palabras clave: Don Guillermo, Valparaíso, espacio, imaginarios, comunidad.

\section{THE UNFINISHED COMMUNITY: \\ DON GUILLERMO BY JOSÉ VICTORINO LASTARRIA}

The novel Don Guillermo (1860) by José Victorino Lastarria (1817-1888) integrates the space-time of Valparaiso during the conservative decades from 1830 to 1860, emergent space of capital and, at the same time, revolutionary focus due to the geography of the city, its trade union tradition and the political unrest promoted by enlightened and radical groups. Considering this historical subtext and articulating the concepts of space, imaginaries, and community through the concept of chronotope, this research mainly investigates the representation of the port city environment in the literary text. From this point of view, Lastarria's novel is proposed as an anti-utopia in the space of The cave of Chivato, and as a liberal utopia in the modernized space of Valparaiso, establishing a symbolic negotiation with the role of the British community. 
KEYWORDS: Don Guillermo, Valparaíso, space, imaginaries, community.

Recepción: 14/04/2020

Aprobación: 29/12/2020

\section{INTRODUCCIÓN}

Este trabajo indaga la representación de Valparaíso en la novela Don Guillermo (1860) de José Victorino Lastarria (1817-1888), articulando los conceptos de "espacio", "imaginarios" y "comunidad" mediante el concepto de "cronotopo", cuyo aspecto espacial -que necesariamente trae consigo lo histórico y lo social- quiere ponerse bajo la luz de las teorías geográficas de Henri Lefebvre y David Harvey, de lo imaginario de Cornelius Castoriadis y del debate sociológico y filosófico sobre la dicotomía entre comunidad (Gemeinschaft) y sociedad (Gesellschaft). Siguiendo de cerca las observaciones de Mijaíl Bajtín, puede decirse desde un principio que ahí donde resultan inseparables el espacio y el tiempo, me refiero a la representación literaria, también se formulan inseparablemente modos de imaginar el mundo y concebir las relaciones sociales, las comunidades.

Por un lado, tiempo y espacio se compenetran e intercambian atributos: el primero se hace material - es un puente, una rivera, una torre-, el segundo adquiere duración y se hace proceso, y esto a través de la simultaneidad propia de la imagen, que es la forma como aparece al lector el cronotopo literario. En palabras de Bajtín, ahí: "El tiempo se condensa [...], se comprime, se convierte en visible desde el punto de vista artístico: y el espacio, a su vez, se intensifica, penetra en el movimiento del tiempo, del argumento, de la historia" ("Las formas" 238, énfasis mío). Tiempo -histórico, humano, insiste Bajtín-y espacio no cobran materialidad, por supuesto, simplemente al enunciarse como categorías abstractas -una reflexión sobre el tiempo o incluso una minuciosa descripción espacial, tiende a mantenerlos separados, como hace el lenguaje-, sino en repertorios históricos de figuras visuales, de imaginarios constitutivos de la argumentación narrativa:

Acerca de un acontecimiento se puede narrar, informar; se puede, a la vez, dar indicaciones exactas acerca del lugar y tiempo de su realización. Pero el acontecimiento no se convierte en imagen. Es el cronotopo el que ofrece el campo principal para la representación en imágenes de los acontecimientos (Bajtín, "Las formas" 400-401). 
Por otro lado, el cronotopo tendría, como quiero poner de relieve, una dimensión ética que puede leerse cuando Bajtín profundiza en las implicancias de su concepto: "como categoría de la forma y el contenido, determina también (en una medida considerable) la imagen del hombre en la literatura" ("Las formas" 238). Por necesidad, esta imagen del hombre se hace carne en el texto literario no por medio de la puesta en escena de seres aislados, sino, precisamente, a través de relaciones humanas, de interacciones entre personajes, de conflictos y empresas en común, es decir, más directamente mediante la puesta en escena y la figuración literaria de ciertas comunidades, imbricadas de modo inseparable al espacio-tiempo en la imagen cronotópica. Es en este aspecto donde, a mi juicio, se hace presente con mayor intensidad el espesor ideológico del discurso narrativo; es en la comunidad donde reluce, lo quiera o no, ese "punto de vista emotivo-valorativo" inseparable en todo caso, insisto con Bajtín, a las determinaciones espaciotemporales de la literatura ("Las formas" 393). Es en su imagen de comunidad donde, en definitiva, el discurso narrativo nos dice, según se encuentren o desencuentren los personajes y en qué lugar y momento lo hagan, cómo es que a su parecer sería mejor que se organizara la polis.

Debido a la antigüedad de su publicación y al hecho de que se encuentra plenamente instalada en el canon novelístico nacional, Don Guillermo de José Victorino Lastarria posee una amplia recepción crítica ${ }^{1}$. No obstante, las aproximaciones a la obra se han centrado principalmente en su carácter alegórico, en su vínculo histórico-político con el enfrentamiento entre liberales y pelucones en el marco de los decenios conservadores de 1831-1861, así como, en cuanto a su aspecto formal, en la controversia acerca de si es o no la primera en su género al interior de la literatura nacional. En esta tradición, el significante "Chile" ha desplazado casi totalmente al significante "Valparaíso" y, en consecuencia, a la significación específica de la representación del espacio, los imaginarios y las comunidades de ese Valparaíso al que se hace referencia en la composición artística y en la estructura ideológica del texto; es decir, el Valparaíso comercial y cada vez más cosmopolita de la primera mitad y hasta mediados del siglo XIX, donde predomina tensamente la comunidad inglesa, como deja entrever Lastarria y, por mi parte, quisiera enfatizar aquí. Sin embargo, la importancia del elemento espacial para el trasfondo discursivo

Se ubica, según la periodización de Goic, en la segunda generación del periodo romántico, la de 1882 (Brevísima 51). 
de la novela sí ha sido tangencialmente señalada en varios trabajos y al menos dos artículos, como se verá más adelante, dedican sus esfuerzos a esclarecer el papel específico de la ciudad-puerto en la configuración textual.

En "Sobre la estructura narrativa de Don Guillermo de J. V. Lastarria", que en 1964 inicia la crítica moderna de la obra ${ }^{2}$, Cedomil Goic la describe como la primera novela moderna del país y repara luego en su composición híbrida de cuento de hadas y artículo costumbrista: está, por una parte, la mitología folclórica en torno a La cueva del Chivato y, por otra, "la vida de la pequeña ciudad" (32). Mención esta última que, citando de pasada una de las subcategorías del cronotopo bajtiniano, subraya el afán de Lastarria por representar con detenimiento el espacio provinciano, con los imaginarios y comunidades que ahí habitan y se despliegan. Para Goic, en pocas palabras, la representación espacial resulta de la mayor relevancia en términos de la composición novelística: "La novela de Lastarria es espacial, esto es, tiende a convertir la diversidad y plenitud de espacialidades en estrato estructurante del mundo" ("Sobre la estructura" 32). El prólogo de Luis Iñigo Madrigal a la edición de 1972, "Lastarria y Don Guillermo", también repara en la centralidad del espacio, solo aparentemente secundario, por efecto del título onomástico, tal como en la gran novela de Alberto Blest Gana: "Ambas novelas llevan nombres de personajes: [pero] Don Guillermo y Martín Rivas no son novelas de Personaje sino novelas de espacio" (19).

De especial interés para este trabajo es el artículo de Lucía Guerra, "Ideología política y alegoría en Don Guillermo de José Victorino Lastarria" (1981), que se interesa por el despliegue de identidades en el trazado citadino y vincula el itinerario del protagonista con el escenario porteño: "El peregrinaje por diferentes sectores del espacio apunta a la configuración de una totalidad" (22). Sugiere así no solo el valor de sinécdoque de Valparaíso respecto al territorio nacional, sino a su importancia per se para la estructura discursiva de la novela. En su "Sociedad y cultura liberal en el siglo XIX" ([1981]-1997),

2 División establecida por Bernardo Subercaseaux, para quien la crítica previa a Goic se caracteriza por una mirada reduccionista: Don Guillermo como novela política y de crítica social, que recurre a la sátira y a la alegoría, y cuyos méritos artísticos serían más bien reducidos. En esta crítica, añade, "predominan los juicios de valor sobre los descriptivos, opiniones que no forman parte de un análisis sistemático, sino que se basan en impresiones teñidas por la postura del crítico frente al ideario laico y a la tradición liberal" (170-171).

Ocupa el Tomo I de Historia de las ideas y de la cultura en Chile (1997) y reproduce el libro Cultura y sociedad liberal en el siglo XIX. Lastarria, ideología y literatura, publicado en 1981. 
Bernardo Subercaseaux pone igualmente atención en el espacio porteño y, además, en el rol de la comunidad británica en relación con la elaboración alegórica del proyecto liberal al interior de la novela. El autor apunta, refiriéndose al protagonista, que "[e]1 hecho de ser inglés, de visitar tabernas en lugar de jugar cricket y de abandonar una promisoria carrera comercial, ofrecía la posibilidad de convertir al personaje en un instrumento de crítica a la anglificación y al rol que empezaban a tener los británicos en el país, especialmente en Valparaíso" (Subercaseaux 177). Esta postura suspicaz del elemento inglés, potencialmente crítica, observa Subercaseaux, se abandona posteriormente, y se torna más bien celebratoria del "adelanto material de Valparaíso durante el primer decenio conservador" (184). Ante todo, subraya la importancia del espacio y del imaginario del progreso decimonónico de Valparaíso, en el que la comunidad inglesa tiene un papel protagónico. Junto a los análisis de Guerra y Subercaseaux, sobresale el breve artículo de Norman Cortés Larrieu, "Don Guillermo y el Espelunco" (1983), que además de polemizar con Subercaseaux - defendiendo a Goic- acerca de si estamos frente a una alegoría o una novela moderna ${ }^{4}$ y de desentrañar sus niveles

4 Subercaseaux pone en cuestión que, como piensa Goic, Don Guillermo sea una novela moderna, pues primaría en su composición el esquema alegórico y el personaje-idea, y no "la vida cotidiana, el dinero, la familia y las relaciones sociales" (176) de la novela realista europea de los siglos XVIII y XIX. Añade también que "el tiempo, el espacio y los lugares reales descritos en los tres primeros capítulos son principalmente trampolines para lanzarse al mundo simbólico de Espelunco, elementos destinados a facilitar la interpretación alegórica que el autor espera del lector" (Subercaseaux 177). Para Cortés Larrieu "la confusión" de Subercaseaux surge al limitar la novela moderna a los siglos XVIII y XIX y a su interés por "la vida cotidiana, el dinero, la familia y las relaciones sociales" (Subercaseaux 176), cuando Goic está pensando, con Wolfgang Kayser, en la tradición iniciada por el narrador cervantino, por su nuevo modo de narrar y captar el mundo (Larrieu 154-155). Considero por mi parte, en la línea de Subercaseaux, que efectivamente Don Guillermo incorpora la alegoría, y además, como diré más adelante, elementos de la "novela" latina y la hagiografía medieval, inscribiéndose en la genealogía cronotópica de Bajtín -que sin demasiado rigor histórico-etimológico extiende el término "novela" hacia la antigüedad-al representar, junto al itinerario del personaje, ciertos espacios particulares de Valparaíso: principalmente El Almendral y el sector de La cueva del Chivato. Pero tal incorporación, y en esto sigo a Goic, la efectúa con innovaciones propias de la novela moderna. Destaca, en este sentido, el narrador personal que aparece de punta a cabo en Don Guillermo, aunque vaya perdiendo interés por la vida cotidiana de la pequeña ciudad, y aunque el protagonista cuya historia narra, pero de quien antes sabemos todas sus señas -ascendencia y correrías previas-, se interne en el espesor alegórico de Espelunco. La moderna forma de representación de la novela (moderna), siguiendo a Ian Watt, privilegia, por influjo del individualismo capitalista, la experiencia particular del sujeto y la perspectiva 
narrativos desde un enfoque estructuralista, echa luces sobre la relación entre el entorno porteño, la configuración del personaje y su ascendencia británica. Contra lo previsible, dice Cortés Larrieu -en consonancia con Subercaseaux-, dada la injerencia determinante de esa comunidad extranjera en los asuntos financieros y mercantiles de Valparaíso, "la caracterización de Don Guillermo en el plano del marco es francamente admirativa, de gran simpatía por parte del narrador" (157). Al perfilar de este modo al personaje, Lastarria estaría expresando más bien su admiración por la colectividad británica, justamente por el rol que le toca en el enorme progreso material de la ciudad. Aunque Cortés Larrieu se interesa sobre todo en detectar las figuras arquetípicas encarnadas por Don Guillermo Livingston y en recalcar la autonomía del texto literario, logra develar el vínculo entre espacio porteño, imaginario progresista -anticolonial-y comunidad inglesa, al señalar que estamos frente a "[u]n héroe apolíneo, prometeico, surgido en un espacio cosmopolita y mágico para el sentir de los chilenos de la época: Valparaíso" (160).

\section{VA-AL-PARAÍSO: ESPACIO DEL CAPITAL Y FOCO REVOLUCIONARIO}

El espacio porteño presente en la novela es un cronotopo, una elaboración artística -además con lugares y seres maravillosos- de Valparaíso durante la primera mitad del siglo XIX. Espacio referencial y espacio representado no pueden, por lo tanto - es necesario decirlo dado el interés de este trabajo por la relación entre literatura e historia-, identificarse en razón de uno a uno. Sin embargo, el cronotopo literario se origina en el vínculo con espacios sociales reales y, a su modo, los absorbe textualmente en un momento determinado de su historia, cuando ya se encuentran producidos. Así, el cronotopo pasa a formar parte activa del espacio-tiempo que asimila y transforma. Dice Bajtín: "La obra y el mundo representado en ella se incorporan al mundo real y lo enriquecen; y el mundo real se incorpora a la obra y al mundo representado en ella" ("Las formas" 404). Atendiendo a esto y enlazando el concepto de Bajtín -para

subjetiva de esa experiencia, así como la concatenación lógica de los hechos y la especificidad del espacio tiempo en que se desarrollan (9-34). El narrador-siempre opinante y dicharacheroy Don Guillermo Livingston -que tras su experiencia en el inframundo quedará encantado con la bullente ciudad- reúnen todos estos rasgos. 
extremar sus posibilidades críticas - con la tríada conceptual propuesta por el geógrafo Henri Lefebvre, diré que el análisis de los principales cronotopos nos permite identificar perfectamente: 1) la práctica social: la cotidianeidad de los sujetos según los itinerarios diseñados para ellos por la cadena productiva; 2) las representaciones del espacio: los imaginarios abstractos de planificadores, urbanistas y tecnócratas; y 3) los espacios de representación: la ciudad tal como la viven los habitantes bajo la ilusión de inmediatez, de movimiento natural (Lefebvre 97-98). En otras palabras, si pensamos en el protagonista de Don Guillermo, la tríada de Lefebvre nos permite identificar sus movimientos en el entorno social determinado por el trazado citadino predispuesto - pero en movimiento y susceptible de transformaciones-por el sistema económico. Esto a través de la subjetividad del personaje y mediante su experiencia "directa" en el mundo (social), en el espacio donde se proyectan los imaginarios y se desenvuelven las comunidades.

El espacio incorporado en Don Guillermo -el Valparaíso de los decenios conservadores entre 1830 y 1860 - corre vertiginosamente, sobre todo en la década del cuarenta, a formar parte de lo que el geógrafo David Harvey llama en su libro homónimo "espacios del capital". Harvey reconstruye el pensamiento geográfico de Marx, diseminado a lo largo de su obra, y devela con claridad el mecanismo expansivo, y destructivo de personas, lugares y comunidades, propio del capitalismo. Basado en la acumulación por la acumulación, según la fórmula de Marx, el sistema capitalista "forma una fuerza permanentemente revolucionaria que de manera continua y constante remodela el mundo en el que vivimos" (Harvey 256). La clave de este proceso es crear las instancias adecuadas para reinvertir el capital acumulado, es decir, dominar y organizar nuevas áreas geográficas (Harvey 259-260). La ciudad de Valparaíso no es que sufra uno de estos procesos, sino que nace de uno de ellos: es fruto de la reconfiguración espacial -que además transforma las relaciones sociales y tradiciones culturales, la percepción temporal, la memoria y los afectos- de una Latinoamérica subordinada a los tráficos mercantiles y financieros europeos del siglo XIX. Durante el periodo posterior a 1812, Valparaíso fue escogido como un rincón apropiado para que los comerciantes ingleses, llegados a las costas sureñas del continente, pudieran reinvertir sus excedentes de producción (Halperín 5) 5

Con orgulloso tono y en románticos decasílabos, como nuestro himno nacional, el himno de Valparaíso asume a la ciudad como espacio ya integrado en el rumbo mundial del 
Pero, además de constituirse en el primer gran enclave capitalista de Chile, Valparaíso es en ese entonces -y muy probablemente por lo mismo"un foco revolucionario", según descubre Ernesto Guajardo al indagar con ojo crítico la prensa y la historiografía de la época (33). Entre los múltiples factores que contribuyeron a esto, dice leyendo a Vicuña Mackenna, están los contactos internacionales de Valparaíso, los gremios y las asociaciones obreras, así como la topografía de la ciudad: las quebradas son potenciales escondites y los cerros, fortalezas naturales (ibid.). De los tres motines ocurridos entre 1850 y 1851, relacionados a la Sociedad de la Igualdad y a la creciente intervención de los pipiolos en esta, el de Valparaíso -fechado en octubre del 51 y llamado también "la revolución de los sastres"- fue el único "verdadero motín popular donde encontramos, por última vez, el espíritu del '48' chileno y la impronta igualitaria original” (Gazmuri 140). A este se añade después, en 1859, la "asonada liberal, protagonizada por integrantes de los sectores populares de Valparaíso", que Ernesto Guajardo llama "el motín de los rotos" y, añade que "tiene uno de sus antecedentes en la campaña política iniciada el 21 de enero de 1858 con la proclamación de José Victorino Lastarria y Ángel Custodio Gallo como candidatos a diputados" (49). Hay, pues, un vínculo nada desdeñable entre la geografía de la ciudad, su tradición gremial y la agitación política originada por grupos ilustrados y radicales, influidos por la Sociedad de la Igualdad y los pipiolos y, además, por la figura activa de José Victorino Lastarria en Valparaíso y otras ciudades de la hoy llamada Quinta Región durante los años inmediatamente anteriores a que se publicara Don Guillermo.

Por su participación en noviembre de 1850 del primer levantamiento propiciado por la Sociedad de la Igualdad -el Motín de San Felipe-, Lastarria fue exiliado a Lima. Rebeldía igualitaria que, quisiera recalcar, se sustenta en un conocimiento profundo y en una auténtica preocupación por las problemáticas políticas y el desmedro económico y cultural de las provincias. Todavía en los años sesenta, señala Subercaseaux, es esto lo

progreso y como motor y eslabón comercial del resto del país: "El comercio que estrecha los mundos / y que cambia del orbe la faz / brinda a Chile sus dones fecundos / y en sus brazos le afianza, / Valparaíso recibe el impulso / de este nuevo vital elemento / y a Santiago le da movimiento / y a los pueblos del Norte y del Sur" (cit. en Vial 25). Insisto en que la identidad porteña, urbana, como hasta hoy se la conoce, nace en este momento: se funda en el "cambio de faz" y surge gracias al "nuevo vital elemento" del comercio (nótese el cierto oxímoron entre los adjetivos que delata lo contradictorio de fundar tradiciones e identidades). 
que alienta los afanes liberales a ultranza de Lastarria: principalmente las circunstancias políticas del Norte y Valparaíso, "que hacia 1865 ocupan un papel subalterno en el bloque hegemónico y que, por lo tanto, incapaces de perfilar un proyecto nacional de acuerdo con sus intereses, promueven -por omisión- un clima propicio para el voluntarismo ideológico y para el desfase entre el mundo de las ideas y el de la realidad" (202). Salta a la vista, entonces, la motivación de Lastarria para alegorizar en Valparaíso y no en ningún otro lugar esa antiutopía que es Don Guillermo, donde nos dice, con una reducción al absurdo -eso es Espelunco-, cómo es que se está de facto organizando la polis en la actualidad. Y ambienta su discurso literario justamente en el espacio más conveniente para implantar otro tipo de organización: Valparaíso es el territorio propicio, uno de tradición revolucionaria y futuro industrioso, aliados ambos en el liberalismo ideológico, para edificar el paraíso anhelado y luego -si con Lucía Guerra la ciudad-puerto ha de entenderse como figuración de una totalidad-extender su modelo a la nación.

El espacio de representación -el espacio tal como lo experimentan cotidianamente los sujetos- (Lefebvre 98) visible en Don Guillermo es, primero, antes de la entrada del protagonista a Espelunco ${ }^{6}$, todavía el de la división precapitalista en que la ciudad queda partida en dos por La cueva del Chivato ${ }^{7}$, en "aquel paraje donde el mar extendía sus espumas casi hasta el cerro" (Lastarria 245); y a cuyos costados se ubican, hacia el noreste El Almendral y hacia el suroeste el futuro sector portuario. En correspondencia, la novela, y particularmente su desarrollo temporal, tiene un hito en el

6 Como ha señalado reiteradamente la crítica, se trata de un anagrama de "pelucones" y al mismo tiempo, lo dice el escribano en la propia novela (Lastarria 259), de la castellanización de la voz latina spelunca (cueva). Añadiría que el nombre "Espelunco" trae asociaciones terroríficas inmediatas, más efectivas para la alquimia literaria que la indagación etimológica; salta al oído en primer momento el adjetivo "espeluznante".

Está ubicada en calle Esmeralda, en la escalera Concepción, a un costado de $E l$ Mercurio. Cuenta Víctor Rojas Farías que el terror en torno a la cueva se remonta al siglo XVII, cuando se encontraba junto a un espolón de roca-después dinamitado-donde solían naufragar los barcos, atribuyéndose la desgracia a un animal demoniaco pronto identificado con el macho cabrío de la demonología medieval (73). En la misma época se sincretizan ahí creencias cristianas e indígenas: los indios del lugar atribuyen el mal a brujos e imbunches y nace entonces la leyenda de que estos sirven al Chivato (Farías 244-245). Valga poner de relieve la reproducción, a nivel de las creencias populares, de la subordinación colonial, y que evidentemente Lastarria extrajo de estos relatos el material para su novela. En el siglo XIX, ya dinamitado el espolón de piedra, el miedo se seculariza traspasándose a supuestas bandas criminales que habitaban la cueva bajo los actuales cerros Concepción y Alegre (Farías 77). 
encuentro entre Don Guillermo Livingston y el monstruoso Chivato, tras el cual el protagonista ingresa a la cueva. Se hace visible aquí el cronotopo del umbral, que, en palabras de Bajtín, "puede ir también asociado al motivo del encuentro, pero su principal complemento es el cronotopo de la crisis y la ruptura vital" ("Las formas" 399). El encuentro en torno a la cueva, umbral hacia el submundo, frontera y pasadizo del territorio dividido, de hecho, efectúa una crisis y ruptura simultáneas en la biografía del protagonista (casi literal por la golpiza del Chivato) y en la historia de la ciudad. Se produce un antes y un después entre el frívolo inglés que se va "a picos pardos", de salida galante hacia El Almendral, en busca de una "linda almendralina" (Lastarria 242-243) y, luego de su encuentro con Lucero en la cueva, el defensor a toda costa de un patriótico -y entonces algo contradictorio- liberalismo ideológico. A la vez, se produce un antes y un después entre el Valparaíso semirural, donde el cura del pueblo decide el casamiento inmediato de la adolescente sorprendida en fragante escarceo amoroso (Lastarria 251) y, pasados veinte $a_{n ̃ o s}^{8}$, el espacio de la impresionante ciudad modernizada que el protagonista vislumbra desde los cerros hacia el final de la novela: "y desde allí descubrieron sus ojos una ciudad extensa, cuyas calles se prolongaban a la orilla del mar, formadas por edificios galantes, limpios y de variados colores. Sintió el bullicio, y en las casas que faldeaban las colinas más próximas, vio el movimiento de los habitantes" (Lastarria 331). Aparece aquí el espacio representado (Lefebvre 97): el mapa modificado, racionalizado por y para los flujos de las finanzas y el mercado, la ciudad como bullente espectáculo cuyos entramados y actividades solo son comprensibles a distancia, desde la altura, prefigurando la novela el que podríamos llamar "cronotopo del mirador porteño". Se trata propiamente del nuevo espacio del capital, en

\footnotetext{
La "historia" de la novela u cronología, en el sentido narratológico, sería la siguiente: 1828: entrada de Don Guillermo a La cueva del Chivato. Transcurren 13 años. 1841: salida, encuentro con el narrador en la posada de El águila y comienzo del peregrinaje entre Santiago y Valparaíso. Transcurren casi 19 años (en un momento indefinido de este periodo, nuevo encuentro con el narrador en Casablanca y caminata de tres días hasta Santiago, donde Don Guillermo le cuenta su aventura en la cueva). 1860: encuentro de un inglés con un envejecido Don Guillermo. 1968: el narrador se entera del despeñamiento y muerte del personaje durante su peregrinación.

Según el narrador, Don Guillermo está en "la cumbre de una montaña" y desciende por el "camino de Carretas" (Lastarria 330). Su actitud nostálgica-reflexiva ante el panorama, actitud de consciencia histórica, se mantendrá en la narrativa porteña al aparecer los miradores y casas con vista al mar.
} 
explosivo crecimiento cosmopolita justamente entre el paso del primer al segundo decenio conservador y en alianza con los ingleses, a despecho del patriotismo liberal por el cual hará Don Guillermo su peregrinaje ${ }^{10}$. Quizá por este despecho, junto a la euforia de la cita anterior, aparece una nostálgica resistencia al cambio: “¡No!, exclamó tristemente, no. ¡Valparaíso no es ese, no es tan grande, no es así! ¡Adónde estoy!” (Lastarria 331). Pero sin duda, sobre este pasajero sentimiento pasatista, predomina la seducción de la ciudad prometeica.

\section{IMAGINARIOS INFERNALES Y FILIACIONES PARRICIDAS}

Los alzamientos porteños promovidos por igualitarios y liberales, con importante iniciativa y participación popular, más las filiaciones estilísticas de Lastarria, se incorporan a la novela, propongo, como un repertorio de imágenes de ruptura y renovación que se compenetra con el espacio-tiempo representado y las relaciones sociales de la ciudad material que este incluye. Para Cornelius Castoriadis lo imaginario es, precisamente, un compuesto de imágenes que posee una función simbólica -representan otra cosa- (204), y que no puede explicarse solo por necesidades naturales, pues cada sociedad imagina la solución a sus problemas de modo distinto y así genera excedentes de sentido o "residuos" (189). Entre lo natural y lo histórico, lo imaginario les asigna y al mismo tiempo les abre nuevas instancias a los individuos. Es un lenguaje con sus propias reglas, pero también con múltiples posibilidades, pues el simbolismo con el que se expresa "a la vez determina unos aspectos de la vida y de la sociedad (y no solamente aquellos que se suponía que

10 En una de las notas a la edición de 1885, Lastarria critica "la devoción al gobierno absoluto de los comerciantes ingleses, residentes en el país, los cuales habían hecho causa común con el partido dominante, hasta el extremo de contarse algunos de ellos que se habían constituido en jefes del partido en Valparaíso, y se entendían como tales con los gobernantes" (285). Pero este patriotismo entra en contradicción con el ímpetu liberal de Lastarria, lo cual es manifiesto en la descripción "culposa" de la ciudad en crecimiento. Subercaseaux se refiere a esto: "La novela, empero, a pesar del autor, revela las contradicciones que conlleva esta postura: el inglés con su fe y su constancia liberal no consigue transformar la realidad, y su perseverancia o su triunfo -si es que lo hay- es solo un triunfo moral; mientras tanto, el único momento de transformación y de progreso representado en la obra corresponde, paradójicamente, al progreso que constata don Guillermo cuando sale de Espelunco, el adelanto material de Valparaíso durante el primer decenio conservador" (184). 
determinaba) y está lleno de intersticios y de grados de libertad" (Castoriadis 202). Así, la novela es, desde este punto de vista, uno de los tantos dispositivos culturales simbólicos desde donde cabe imaginar resoluciones a ciertas problemáticas de orden social.

En términos de filiación literaria, el imaginario de Lastarria comienza abriendo "intersticios y grados de libertad" (Castoriadis 202) al emparentarse oblicuamente -si atendemos al narrador cuando Don Guillermo se escandaliza por el respeto ilimitado a las jerarquías en La cueva del Chivato- con esa genealogía de "escritores parricidas" y "maledicentes", "deslenguados y sarcásticos", autores de Cándido, El Quijote, Los viajes de Gulliver y Tristram Shandy, entre otros (Lastarria 284), afines al realismo grotesco descrito por Bajtín en su estudio sobre François Rabelais. Los insultos y diatribas, los dichos y refranes pertenecientes a esta concepción suelen enviar a su destinatario, dice Bajtín, "al lugar 'inferior' corporal absoluto, a la región genital o a la tumba corporal (o infiernos corporales) donde será destruido y engendrado de nuevo" (La cultura popular 31). La temática y la estructura narrativa infernal de Don Guillermo, su katabasis de filiación dantesca, se encuentra, por lo tanto, mediada no solo por el impulso crítico de las obras carnavalescas que menciona el narrador -las de Voltaire, Cervantes, Swift y Sterne-, sino también por algunas obras incluso anteriores a Dante, quien, por lo demás, incorporó tradiciones populares en su irruptora mezcla de estilos, fundamental para la representación literaria moderna ${ }^{11}$. Entre las obras narrativas de la antigüedad analizadas por Bajtín, se encuentra El asno de oro de Apuleyo, (siglo II d. C.), de clara estirpe carnavalesca, cuyo motivo de la metamorfosis, resignificado posteriormente por las hagiografías medievales, se actualiza a mi modo de ver en la novela de Lastarria. Dice Bajtín que:

Sobre la base de la metamorfosis se crea un tipo de representación de toda la vida humana en sus momentos cruciales, críticos: la manera en que el hombre se convierte en otro. Son representadas las diversas imágenes, claramente diferentes, de la misma persona, reunidas en ella como épocas y etapas diferentes de su existencia. No se da aquí

11 En nadie como en Dante, dice Erich Auerbach al estudiar el proceso representacional de la literatura europea, de donde bebe Lastarria, "se hizo tan visible el antagonismo de ambas tradiciones -la antigua, con su separación estilística, la cristiana con su mezcla-como en este poderoso temperamento, que cobra conciencia de ambas [...] Nunca se acercó tanto la mezcla de estilos, a la ruptura del estilo" (179). 
un proceso de formación en sentido estricto, sino que se produce una crisis y un renacimiento ("Las formas" 268, cursivas en el original).

Particularmente en las hagiografías se presentan tres momentos determinantes para la trayectoria vital de los santos. Estos serían: el momento previo a la crisis espiritual, el momento propiamente de la crisis -el de la bajada a los infiernos de la conciencia- y el de la conversión o renacimiento (Bajtín, "Las formas" 268-269). Esta estructura del espacio-tiempo novelesco en consonancia con la experiencia vital del protagonista es palmaria en Don Guillermo, aunque los ímpetus espirituales se traspasen a la esfera política. Como en las hagiografías, se aprecian tres momentos decisivos: el de la salida nocturna "a picos pardos"; el de la crisis infernal en Espelunco, tras el encuentro con el Chivato; y el del peregrinaje entre Santiago y Valparaíso. Replicando la metamorfosis de la novela latina y las hagiografías medievales, el proceso de "culpa-castigoexpiación-beatitud" (Bajtín, "Las formas" 271), Don Guillermo Livingston se transforma en una suerte de sacerdote -en este caso, en uno del liberalismo ideológico-que, a diferencia de los santos, no alcanza el estado de beatitud. Esta diferencia es crucial. La novela no encuentra la resolución de sus modelos; parece trunca comparada con las estructuras narrativas premodernas. Pero es que en este punto el personaje y la trama muestran su especificidad histórica y su filiación discursiva a eso que Lukács ha llamado el "romanticismo de la decepción", es decir, "el deseo sobre-dimensionado, sobre-determinado de una vida ideal, en contraposición a la real; el reconocimiento de que ese deseo está condenado a ser insatisfecho; una utopía basada desde el inicio en la incómoda certeza de la derrota" (115). El héroe romántico, marcadamente pasivo -lejos del confrontacional idealismo abstracto de un Don Quijote, por ejemplo-, termina derrotado por las pétreas imposiciones de la realidad, que así solo demuestran su bajeza frente a la Idea.

Pero en Don Guillermo el fracaso no opera solo como un contraste para exaltar al héroe. El protagonista muere sin cumplir su misión -peregrinar durante veinte años y realizar tres mil viajes entre Santiago y Valparaíso para encontrar el talismán del patriotismo perdido en una de las dos ciudades (Lastarria 271)-y el tiempo histórico se muestra como inconcluso para alentar la disconformidad. En opinión de Gastón Carrasco, la intención de Lastarria es traspasar al demos (al pueblo) la praxis política que se ha visto truncada con la muerte (264). La resolución novelística, la beatitud no alcanzada por Don Guillermo, puede añadirse a esta lectura, se traspasa al narrador testigo y de este al lector, gracias a la demoniaca capacidad metamórfica del protagonista 
al narrar -y traspasar como una visión-su bajada a los infiernos en la caminata a Santiago: "tres días durante los cuales vi y oi [dice el narrador] las cosas más asombrosas que jamás he visto y oído, tres días durante los cuales se transformó cien veces Mr. Livingston, tres días en fin en que yo fui también a mi turno metamorfoseado a cada paso por mi compañero" (Lastarria 239, cursivas en el original).

El imaginario demoniaco resulta de la mayor importancia ideológica. En su análisis de la narrativa de Lastarria, Subercaseaux detecta al menos dos formas de personificación diabólica. Por una parte, en El manuscrito del Diablo (1849) aparece el proscrito amigo de los hombres, el "beaux tenebraux de la literatura romántica europea, el diablo dandy y seductor, el demonio elegante, vestido con levita, casi siempre extranjero y de edad indeterminada" (131). Por otra parte, en Peregrinación de una vinchuca (1858) se hace presente el terrorífico enemigo de Dios y de los hombres, cuya imagen contribuye a preservar el poder religioso: "el Satanás de la tradición medieval, con los círculos y la corte que imaginó Dante y las figuras grotescas que pintó Hieronymus Bosch" (137). En mi opinión, los dos aparecen en Don Guillermo. El Chivato es, sin lugar a dudas, la reconstrucción porteña, a punta de supersticiones locales, del diablo medieval-pelucón; y -menos evidentemente-Guillermo Livingston encarna al diablo ilustrado-romántico, amigo y liberador de los proscritos, como él mismo lo es. Se sugiere en la inquietante caracterización de la patrona del hotel de Europa, donde se aloja: "es hombre muy extraordinario, habla con los espíritus, no duerme, se ríe solo, se pasea a la media noche, se encierra de día, no tiene equipaje, y sin embargo le sobra el dinero en su faltriquera..." (Lastarria 235). Juntos y complementariamente, ambos encarnan el tránsito histórico-político nacional en correspondencia al cronotopo de la novela, donde cada espacio porta una historia y un modo opuesto de pensar la sociedad. El Chivato, el pavoroso diablo del Medioevo, se corresponde con el espacio premoderno de la Colonia que persiste en El Almendral y, sobre todo, en la cueva donde se enraíza malignamente ese pasado. Mientras, Don Guillermo, el diablo ilustrado y romántico, pipiolo e igualitario, se corresponde con el espacio del liberalismo económico que despliega sus promesas en el sector portuario en vías de modernización.

Este imaginario de filiación literaria crítica y liberadora-pues evidentemente el lector debe identificarse con Don Guillermo, el héroe romántico, y no con el Chivato, su opuesto ideológico-se retroalimenta en la novela con el imaginario social del Valparaíso de la época, según el cual, dice el historiador Santiago 
Lorenzo, los porteños creen vivir en una sociedad más libre e igualitaria que la capital y contraria a los "hábitos aristocráticos" (138-139). Esto se sustentaría en los diversos orígenes sociohistóricos: mientras Santiago surge de una elite tradicional que se remonta a la Colonia, Valparaíso, en cambio, es "hija de la República", "nació en la Independencia"; se trata de una ciudad cuyo trazado urbano y reticulado social, como hasta hoy lo conocemos, se confecciona al ritmo de un vertiginoso crecimiento económico y es, por lo tanto, "una ciudad improvisada por el comercio" (Estrada 42-44). En este punto se hace evidente que La cueva del Chivato y su conservadurismo extremo alegoriza, junto a muchas otras cosas, el espacio geopolítico capitalino, que aún sufre el peso de la noche colonial mientras Valparaíso da lugar a "una sociedad que no arrastra el peso de una estructura social preestablecida que imponga su estilo" (Estrada 44).

Los tránsitos del protagonista, a través de un espacio configurado en la representación por los imaginarios literarios y sociales ya mencionados, adquieren un talante transgresor propio. Si bien la arquitectura urbana y su entramado ideológico produce y reproduce lo ya establecido, "la división entre ricos y pobres, entre poderosos y subalternos, entre hombres y mujeres" (Guerra 13), también es cierto que, "a ese nivel concreto del suelo y lo topográfico, es constantemente transgredida por la presencia y el tránsito de los excluidos por esa estructura de poder" (ibid.). Bajo este enfoque, el Valparaíso imaginado por Lastarria, al configurarse en la representación como espacio del capital y, en contrapunto, como foco revolucionario, abre la posibilidad de que surja ese proscrito que es Don Guillermo Livingston, con su libre itinerario -su "práctica social", diría Lefebvre- por hoteles, fondas, entornos rurales, bordes costeros y caminos; figura transgresora que tanto puede caer en un infierno conservador, Espelunco, como escenificar el intento de acabar con él mediante un peregrinaje redentor, y en este sentido es irrelevante su derrota final.

\section{UNA MODERNA COMUNIDAD ESENCIAL}

Los espacios y sus imaginarios no son producidos y reproducidos por sujetos aislados, sino por agrupaciones humanas, por comunidades, y lo mismo puede decirse en relación al texto literario: los espacios e imaginarios se elaboran y condensan con relaciones sociales. Las primeras teorizaciones sobre el concepto de "comunidad" pensaron dos tipos básicos que se 
discuten y actualizan hasta la fecha. Como el título de su obra de 1887, Gemeinschaft und Gesellschaft, comunidad y asociación (o sociedad) denominó el sociólogo alemán Ferdinand Tönnies a estas dos modalidades. La primera se encuentra cohesionada por la sangre, por el lugar o por el espíritu, es decir: por parentesco, por vecindad o por el trabajo cooperativo hacia una meta conjunta (Tönnies 100). Esta comunidad tradicional o Gemeinschaft arrastrará tópicamente en la teoría todo un imaginario de lo íntimo y hogareño, de la pequeña comarca rural y el trabajo de los artesanos, del lugar ameno. El segundo tipo de comunidad descrito por Tönnies es la asociación o lo que conocemos por sociedad moderna, "compuesta por convención y derecho natural, [y que] ha de entenderse como una multitud de individuos naturales y artificiales, cuyas voluntades y esferas mantienen muchas relaciones entre sí, quedando sin embargo independientes y libres de las relaciones familiares mutuas" (Tönnies 152). Es la comunidad impersonal de la sociedad burguesa centrada en el beneficio personal, la misma que despertó la alarma de Hegel y la nostalgia de los poetas románticos alemanes, donde la vida espiritual, los pequeños poblados familiares y la poesía no tienen ya cabida.

En Don Guillermo se presenta, primeramente, en La cueva del Chivato, una Gemeinschaft o comunidad tradicional, cohesionada por el principio de autoridad hereditaria: el poder de la sangre, del territorio y la cultura española defendida por "los genios de la colonia, que se han refugiado aquí desde la revolución de la Independencia" (Lastarria 258). Pero el impulso crítico de la novela hace de esta una comunidad indeseable: Lastarria extrema hasta el absurdo los principios de la Gemeinschaft y así Espelunco se erige como un antimodelo, como una anticomunidad. Y lo hace mediante el subgénero de las antiutopías, donde se despliega "[e]l ideario ya no de ciudades maravillosas, sino de relatos de un caos, que de igual forma pretende ser lugar de denuncia de su posibilidad de constitución" (Zuchel 23). Espelunco es, para mayor precisión, un "orden invertido" de las relaciones sociales, respecto de cuya evaluación negativa la novela no tiene ambigüedades, y echa andar por eso "un tipo de antiutopismo que no quiere que prevalezca el estado factual" (Zuchel 38). Al mismo tiempo, como ya he sugerido, Don Guillermo puede leerse al estilo de las utopías propiamente tales ${ }^{12}$ : tras la salida del infierno se

12 Según la nomenclatura de Zuchel, Utopía (1516) de Tomás Moro sería una "utopía liberadora", mientras Un mundo feliz (1932) de Aldous Huxley -así como Don Guillermo 
ofrece al lector, en la mirada del inmigrante inglés, la visión esperanzadora del industrioso (Val)paraíso de la superficie. Lastarria se inscribe con esta lectura en una renovación latinoamericana del género utópico, desarrollada entre mediados del siglo XIX y principios del XX. En estos textos:

se descubren nuevos espacios que conquistar, nuevos territorios donde grupos étnicos, religiosos o políticos pueden instalarse libremente. Las localidades que evocan el Paraíso perdido desde su propio nombre, se multiplican: Puerto Alegre, Ciudad Paraíso, Puerto Edén, Valparaíso, pueblan la nueva geografía humana del continente (Aínsa 35).

Valparaíso aparece, por encima de La cueva del Chivato, como el territorio y la comunidad prometida, por su nacimiento independiente y su talante liberal e incluso revolucionario, ciudad constituida por inmigrantes y viajeros de paso, formada por un crecimiento material de impronta cosmopolita, que le otorga un aire democrático de apertura al mundo. Cobra sentido, pues, el hecho de que el protagonista de la novela, Don Guillermo Livingston, sea precisamente un inmigrante inglés. Si en un primer momento, anota Bernardo Subercaseaux, esto se ofrece como "instrumento de crítica a la anglificación y al rol que empezaban a tener los británicos en el país, especialmente en Valparaíso" (178), luego tal posibilidad se diluye en "el paso a un personaje alegórico, a la encarnación exclusiva de un concepto abstracto o de una idea" (ibid.). El comentario detecta, de hecho, cómo la novela escenifica la transformación de los imaginarios de la sociedad porteña con respecto a los inmigrantes ingleses. En la década de 1830, se lamenta la extranjerización u ocultación de las costumbres autóctonas por su causa (Lorenzo 137), y décadas más tarde se celebran el éxito económico, las costumbres elegantes, el cambio vertiginoso -en contraste con Santiago- impulsado por esa comunidad. El Mercurio del 8 de diciembre de 1850 evidencia lo anterior: "El comerciante que va a Valparaíso cada seis meses se asombra de ver cosas nuevas que

de Lastarria, propongo-, "antiutopías liberadoras". Además, está el caso de las "antiutopías estancadas" en que el caos no presenta alternativa. Se desprende de esta lógica una "utopía estancada", y como ejemplo pienso en la novela Synco (2008) de Jorge Baradit donde una Unidad Popular sin golpe de Estado conduce a una dictadura socialista. Simplificando y complementando a Zuchel (en el punto cuatro), se dan las siguientes posibilidades de narrativa utópica: 1) la utopía conduce a la utopía; 2) el caos conduce a la utopía; 3) el caos conduce al caos; y 4) la utopía conduce al caos. 
sorprenden sus miradas; el que viene a Santiago cada diez años, reconoce a primera vista sus calles, casas y hasta por los accidentes mezquinos que las distinguen" (cit. en Estrada 33). Asimismo, en los primeros capítulos de la novela, el temple del narrador es desconfiado, acomplejado en relación al protagonista, y acusa: "ese desprecio con que los ingleses o sus descendientes los yankees, miran a todos los que les hablan en español" (Lastarria 233). Pero luego, en Espelunco, es Don Guillermo el encargado de recobrar "el talismán del patriotismo perdido" (Lastarria 335) y quien contempla maravillado, con la euforia descriptiva de las utopías clásicas, la renovación arquitectónica de la ciudad-puerto propiciada por sus compatriotas, en todas esas calles "formadas por edificios galantes, limpios y de variados colores” (Lastarria 331).

Aquí se responde en parte a la pregunta de por qué Lastarria no reservaba la misma y célebre acritud al (neo)colonialismo inglés que al viejo colonialismo español y su peso nocturno aún presente en esos tiempos. Y es que, mientras España simboliza el oscurantismo y el anquilosamiento en todos los ámbitos del desarrollo humano, Inglaterra representa al liberalismo en su acepción más revolucionaria, como doctrina de (supuesta) libertad de conciencia y libertad de acción. La comunidad británica promete convertir a Chile, y a Valparaíso en particular, no en una colonia inglesa, sino en algo más bien semejante a Estados Unidos ${ }^{13}$, ese paraíso de libertad, igualdad y fraternidad, a ojos de Lastarria. Por eso, en el estilo de la elite, "[a]l mismo tiempo que [él] y sus discípulos batallaban por emancipar la cultura chilena, mostraban -amparados en el laissez faire y en el librecambismo- una actitud pasiva y más bien favorable a la entrega del cabotaje, del comercio y de los recursos básicos del país a capitales extranjeros, fundamentalmente ingleses" (Subercaseaux 157). Don Guillermo es la figura ideal en este sentido: inglés de nacimiento, pero norteamericano "por afección y casi por principios, porque he pasado en Estados Unidos lo mejor de mi vida" (Lastarria 230). En consonancia con

13 En el marco del siglo XIX, Enrique Krauze se refiere a un "ciclo de admiración y desencanto" de Hispanoamérica con respecto a EE. UU., a quien miró con admiración durante la consolidación de sus nuevas naciones independientes. EE. UU. representaba el modelo de orden constitucional y prosperidad económica para las nuevas naciones, el reverso de la monarquía española. Incluso tras la intervención en México, en 1846, y la consiguiente sustracción de Texas, el desencanto es parcial. Se instaura definitivamente con la humillación a España en 1898, cuando pierde sus últimas colonias en el continente. Los círculos liberales convergieron con los conservadores y se replegaron juntos en cierto nacionalismo hispanoamericano, cuya Biblia, al decir de Krauze, fue el Ariel de Rodó (48). 
el ideario de su autor, anota Alexis Candia, "Livingston responde a las dos naciones que marcan, en la perspectiva de Lastarria, la ruta del progreso en el siglo XIX y, por consiguiente, se oponen al pasado oscuro, conservador, colonial del dominio español" (96).

La comunidad británica de Valparaíso, que en su carismático representante funde el donaire y pragmatismo inglés con los vientos modernos, triunfales del liberalismo estadounidense, promete, pues, junto a la emergencia del "pueblo", algo inverso a la anticomunidad de Espelunco, cohesionada por castas y privilegios, por la separación y no por lo común. Si en el presente ese proyecto es solo una utopía y una ucronía, ya tiene reservado un espacio (Valparaíso) y un tiempo (el futuro), y la muerte de Don Guillermo en medio de su peregrinación, la muerte simbólica del elemento inglés a quien sobrevivirá el pueblo, deja en claro quién deberá predominar ahí. No se inscribe esta comunidad, por cierto, en las "extrañas comunidades" del más reciente debate filosófico en torno al concepto ${ }^{14}$. No es la comunidad que viene, como la piensa Giorgio Agamben, "una comunidad inesencial, de un convenir que no concierne en modo alguno a una esencia" (30), ni tampoco, con Roberto Esposito, puede decirse que "[n]o es una posesión, sino, por el contrario, una deuda, una prenda, un don-a-dar" (30). Se trata, en cambio, de una comunidad sustentada, valga la paradoja - que es la de la nación-, en una esencia recientemente conquistada (creada) durante la Independencia y extraviada por causa del dominio pelucón. “[E]1 talismán del patriotismo perdido" (Lastarria 335) es la posesión virtual de una Gemeinschaft democrática, actualización moderna de la comunidad íntima y cerrada y no -por cándido que parezca tras el triunfo del liberalismo económico sobre el liberalismo ideológico- una mera Gesellschaft o sociedad basada en el frío interés personal. Su pérdida reciente insufla el idealismo heroico de Don Guillermo y la exuberancia imaginativa de la novela: tal comunidad puede reconquistarse si se concientiza y actúa contra el oscurantismo evidenciado, en toda su absurda y terrorífica magnitud, por La cueva del Chivato y gracias al contraste de Espelunco con la prometeica ciudad de Valparaíso, donde a su salida del infierno el protagonista logra ver, como el Dante peregrino, "las

14 Aquí hago referencia al artículo de Mónica Cragnolini "Extrañas comunidades: para una metafísica del exilio" -incluido en su libro Extrañas comunidades. La impronta nietzscheana en el debate Contemporáneo. Buenos Aires, La Cebra, 2009-, donde revisa la discusión a la luz de la influencia nietzscheana, el amor fati y la extrañeza como base de la experiencia vital. 
últimas ondas de aquel éter dulcísimo que azula nuestro cielo en un día de invierno" (Lastarria 330).

\section{CONCLUSIÓN RETROTÓPICA}

En su novela, Lastarria imagina y hace visible el proyecto pelucón al modo de una "retrotopía", entendida con Zygmunt Bauman como esos "mundos ideales ubicados en un pasado perdido/robado/abandonado que, aun así, se ha resistido a morir, y no [como lo está la utopía] en ese futuro por nacer (y, por lo tanto, inexistente)" $(14)^{15}$. Mediante una composición del lugar infernal de hiperbólico conservadurismo, reduciendo al absurdo los principios de la Gemeinschaft o comunidad tradicional, pretende evidenciar cuán perniciosas pueden llegar a ser las consecuencias del culto al pasado, y erige Espelunco como una antiutopía u orden invertido de las relaciones sociales a las que aspira la modernidad liberal de Guillermo Livingston.

Los imaginarios y modelos literarios -lo carnavalesco, lo hagiográficometamórfico, lo infernal o diabólico-, así como los imaginarios sociales de Valparaíso - los de una comunidad inglesa mirada con reticencia al principio y con creciente admiración al correr del tiempo-, se acumulan densamente en la novela para apuntalar la idea de progreso y proyectarla en todos sus componentes: en el espacio de Valparaíso, primero dividido y rural, luego integrado y modernizado; en el personaje de Guillermo Livingston, movido al comienzo solo por su lúbrico individualismo y después, pasando desde la culpa al castigo y la redención, por un proyecto colectivo; y en la temporalidad histórica del relato: el Valparaíso de la primera mitad del siglo XIX, con su pasado inmediato de estructura precapitalista y su presente ungido por el transcurso homogéneo y vacío del capital y la renovación urbana. Todo esto se condensa en el cronotopo del umbral, vuelto imagen en La cueva del Chivato y cuyo trasunto ideológico es la crisis y la ruptura vital.

El reverso de la antiutopía de Espelunco es la utopía de retomar a futuro la inconclusa comunidad del patriotismo conquistado por la Independencia, en

15 Apoyándose en varios autores, Bauman explica el impulso retrotópico como una respueta nostálgica frente al sentimiento de discontinuidad, ruptura y fragmentación a finales del siglo XX (12). Me parece lícito trasponerlo a un contexto en que, al menos desde la posición afectiva de los más conservadores, ocurría algo parecido al romperse el vínculo colonial. 
una alianza con la inmigración británica que contribuiría a encauzarnos hacia la vía del éxito económico al estilo de Estados Unidos: Don Guillermo, según él mismo dice, es inglés de nacimiento, pero norteamericano por afección y principios. Su muerte heroica, sacrificial, deja en claro dos cosas: por un lado, la altura de su ideal y, por otro, quién deberá predominar en la nueva comunidad, lo cual se declara sin rodeos hacia el final de la novela: el románticamente idealizado pueblo. El Valparaíso urbano, espacio configurado según las lógicas del capital, pero con una cronología de revueltas sociales -"la revolución de los sastres" (1851), "el motín de los rotos" (1859)-, y de nombre salvífico, es el cronotopo edénico indicado para dar realización a ese proyecto de una Gemeinschaft democrática, actualización moderna de la comunidad íntima y cerrada y opuesta tanto a la Gesellschaft o sociedad basada en el frío interés personal como a la comunidad retrotópica, que aspira a restaurar la Colonia y tiene su hegemonía en el Santiago pelucón alegorizado por La cueva del Chivato. Sinécdoque de una comunidad nacional inconclusa, proyectada literariamente en un espacio-tiempo y en unos imaginarios inestables, llenos de contradicciones, la ciudad-puerto, Valparaíso, adelanta en Don Guillermo la posibilidad de concretar la utopía de otra comunidad.

\section{BIBLIOGRAFÍA}

Agamben, Giorgio. La comunidad que viene. Valencia, Pre-Textos, 1996.

Aínsa, Fernando. Necesidad de la utopía. Montevideo, Tupac Ediciones y Nordam, 1990.

Auerbach, Erich. "Farinata y Cavalcante". Mimesis. La representación de la realidad en la literatura occidental. Ciudad de México, Fondo de Cultura Económica, 1996.

Bajtín, Misaíl. La cultura popular en la Edad Media y en el Renacimiento. El contexto de François Rabelais. Madrid, Alianza, 1990.

"Las formas del tiempo y del cronotopo en la novela. Ensayos de poética histórica". Teoría y estética de la novela. Trabajos de investigación. Madrid, Taurus, 1989.

Bauman, Zygmunt. Retrotopía. Buenos Aires, Paidós, 2017.

CANDIA CÁCERES, AleXIs. "'Piel de culebra': Representaciones literarias de la inmigración en Valparaíso durante los siglos XIX y XX". Chasqui: Revista de Literatura Latinoamericana XLIX, N², 2020, pp. 90-106.

CARrasco, Gastón. "La libertad de los románticos: alegoría y ansiedad en Don Guillermo". Los pactos de la República: modernidad y secularización. El diablo en la literatura chilena del siglo XIX. Tesis para optar al grado de Doctor en Literatura. Santiago, Pontificia Universidad Católica de Chile, 2018.

CAstoriadis, Cornelius. La institución imaginaria de la sociedad. Barcelona, Tusquets, 1975. 
Cortés Larrieu, Norman. "Don Guillermo y el Espelunco". Valparaíso. Visión multidisciplinaria III-IV. Valparaíso, Academia Superior de Ciencias Pedagógicas de Valparaíso, 1983.

Esposito, Roberto. Communitas: origen y destino de la comunidad. Buenos Aires, Amorrortu, 2012.

Estrada, Baldomero. "Poblamiento e inmigración en una ciudad-puerto. Valparaíso 18201920". Valparaíso. Sociedad y economía en el siglo XIX. Baldomero Estrada T., Eduardo Cavieres F., Karin Schmutzer S. y Luz María Méndez (comp.). Valparaíso, Ediciones Universitarias de Valparaíso de la Universidad Católica de Valparaíso, 2000.

GAZMURi, Cristián. El “48” chileno. Igualitarios, radicales, reformistas, masones y bomberos. Santiago, RIL, 2019.

Goic, Cedomil. "Sobre la estructura narrativa de Don Guillermo de J. V. Lastarria". Revista del Pacífico 1, 1964, pp. 61-71.

Brevísima relación de la historia de la novela hispanoamericana. Madrid, Biblioteca Nueva, 2009.

Guajardo, ERnesto. Valparaíso. La memoria dispersa. Santiago, RIL, 2013.

Guerra Cunningham, Lucía. Ciudad, género e imaginarios urbanos en la narrativa latinoamericana. Santiago, Cuarto Propio, 2014.

"Ideología política y alegoría en Don Guillermo de José Victoriano Lastarria". Cuadernos Americanos 40, 1981, pp. 13-28.

Halperín Donghi, Tulio. "Economía y sociedad". Historia de América Latina. 6. América Latina Independiente, 1820-1870. Leslie Bethell (comp.). Barcelona, Crítica, 1991.

HARVEY, DAVID. "La geografía de la acumulación capitalista: reconstrucción de la teoría marxiana”. Espacios del capital. Hacia una geografía crítica. Madrid, Akal, 2007.

Krauze, Enrique. Redentores. Ideas y poder en América Latina. Barcelona, Debate, 2011.

Lastarria, José Victorino. "Don Guillermo”. Obra narrativa. Santiago, Ediciones Universidad Alberto Hurtado, 2014.

Lefebvre, Henri. La producción del espacio. Madrid, Capitán Swing, 2013.

Loyola, Hernán. “Don Guillermo y Martín Rivas: visión en paralelo”. La novela hispanoamericana. Descubrimiento e invención de América. Valparaíso, Universitaria, 1973.

Lorenzo, Santiago. "Imaginarios de Valparaíso, siglos XIX y XX”. Boletín de la Academia Chilena de la Historia 110, 2000-2001, pp. 131-150.

LuKÁCs, György. Teoría de la novela. Un ensayo histórico-filosófico sobre las formas de la gran literatura épica. Buenos Aires, Ediciones Godot, 2010.

Madrigal, Luis IÑIgo. "Lastarria y Don Guillermo". Don Guillermo. José Victorino Lastarria. Santiago, Nascimento, 1972.

Rojas Farías, Víctor. Valparaíso, el mito y sus leyendas. Santiago, RIL, 2001.

Subercaseaux, Bernardo. "Sociedad y cultura liberal en el siglo XIX: J. V. Lastarria”. Historia de las ideas y de la cultura en Chile. Tomo I. Santiago, Universitaria, 1997.

VIAL, SARA. "La música en Valparaíso. Óperas, zarzuelas, serenatas". Valparaíso, el violín de la memoria. Santiago, RIL, 2001. 
Watt, Ian. The Rise of the Novel: Studies in Defoe, Richardson, and Fielding. Berkeley, University of California Press, 1957.

ZuChel, LoRenA. "Sobre utopías, antiutopías y liberación. Aproximaciones y precisiones desde Latinoamérica". Revista de Ciencias Sociales 64, 2014, pp. 13-45. 